\title{
A Sociolinguistic Perspective of WhatsApp Statuses Used by Jordanians
}

\author{
Mohammad Ibrahim Shehabat \\ School of Arts and Languages, Jadara University, Jordan \\ Luqman Rababah \\ School of Arts and Languages, Jadara University, Jordan
}

\author{
Received: June 13, $2021 \quad$ Accepted: August 20, $2021 \quad$ Published: August 28, 2021 \\ doi:10.5296/elr.v7i2.18964ＵRL: https://doi.org/10.5296/elr.v7i2.18964
}

\begin{abstract}
The study aimed to examine the use level of the WhatsApp among Jordanians, and also to identify differences among Jordanians in WhatsApp status uses in light of their gender, age, marital status, and socioeconomic level. The population of the study included all students who are enrolled at the English department of Jadara and Irbid national Universities in Irbid, Jordan. The sample of the study consisted of (262) students whose ages are between 18-40 and were selected randomly. To achieve the aims of the study, a (23) item questionnaire was developed based on previous literature and used for data collection. The results showed that the level of using WhatsApp application among university students was high. The result showed that there are statistically significant differences at $(\mathrm{a}=0.05)$ due to gender in favor of females, due to age in favor of the age group 18-21, and in Socioeconomic level in favor of more than 500. In light of results, the study recommend to work on motivating students for more use of this important application for academic purposes.
\end{abstract}

Keywords: WhatsApp, Statuses, Sociolinguistics

\section{Introduction}

There is no doubt the various communication advances have changed the landscape of human life at all levels. The reliance on social media tools have marked the communication patterns used by people nowadays. Consequently, the messages communicated using these tools have been remarkably a reflection of what people feel, think or behave. The emergence of several social media platforms was a major contributor in changing people's actions and feelings. Social media is one of the most advanced communication tools that have gained enormous popularity in the last few years as an effective instrument for information exchange. It has 
given people the power to choose the content of the messages they wish to communicate to others, in addition to the manner by which they can use to send messages (Ilyas \& Khushi 2012).

As one of the major social media application, WhatsApp was founded in 2009 as one of the media applications by Brian Acton and was later developed by Jan Koum. The emergence of this application was due to the various developments in the different modifications on the available media application in the 30 years before, leading to the appearance of several media applications such as Facebook, Twitter, Instegram, Snapchat and WhatsApp (Wani et al., 2013).

From a sociolinguistic perspective, understanding the content of the social media application status users are communicating to others carries several linguistic messages. For example, using a sad face, some words may signify that the user is experiencing sad events in his life. Using roses and hearts indicate that he/ she are in a romantic relationship. Both Kramer and Chung (2011) indicate in this respect that social media applications provide both psychological and linguistic cues about the state of the user. In other words, analyzing the content of the status provides an insightful look at the personality of the user, his attitudes and preferences. Affirming this, one study (Kramer 2010) used a sample of 400 million accounts on Facebook, analyzed the content of status presented on them and concluded that analyzing these accounts give a clear picture of the users' personality.

Analyzing the content of the messages being communicated by people using a specific media application has been one of the hot topics in the sociolinguistic field. It helps in understanding the emotional and ideological state of the use as it conveys the sentiments and ideas being communicated using this application. For this reason, scholars in the various fields have worked in the last few years on developing some methodological approaches able to assist in being more informed about the status being presented on the social media application so as the recipients of the intended message can effectively manage their responses to these status (Awl, 2011). As WhatsApp is one of the most common social media applications gaining popularity in the recent years, people use it to analyze the status of those users employing it in a manner that enables the other users comprehend the emotional state of those they maybe of sentimental or professional relationship with, and as a way to provide them help. Based on the above discussion, this study aims to find out the semantic messages communicated by Jordanians using WhatsApp application in light of some demographic variables.

\subsection{Statement of the Problem}

The use of social media applications has increased rapidly in the last few years. Although there were many efforts and scientific studies carried out to examine the use of these new forms of communication, there is still a gap in previous research dictating the need for more studies investigating the use of social media applications as a means for communication among users, and this what motivated the researchers to examine the sociolinguistic functions of WhatsApp statuses messages. In other words, previous studies that investigated the sociolinguistic functions of WhatsApp statuses are very scarce (Abu Swailam, 2015). Thus, this justifies conducting such a study to fill a gap in the previous literature and to and answer the calls made by other researchers (Garcia \& Sikstrom, 2013). 
As the status of WhatsApp uses among the various populations is still in its beginnings, especially from a sociolinguistic perspective, the absence of suitable academic research material for this topic highlights the importance of this study. It is anticipated that the findings of this research will, if properly conducted, assist Jordanians from various age groups and backgrounds to be more attentive to the status communicated in social media in general and WhatsApp in particular as being a tool to understand the emotional state of the user. It is, then, of great significance to examine the various variables related to the use of social media tools among people from the various levels. Emphasizing the increasing percentage of social media users, both Ilyas and Khushi (2012) estimate that the users of social media increases by $5 \%$ each year worldwide and this increase is due to the elevating access to the internet.

\subsection{Questions of the Study}

The study considers the following questions:

1- What is the level of WhatsApp use among Jordanians?

2- Are there any differences among Jordanians in using WhatsApp status in light of their gender, age, marital status, and socioeconomic level?

\subsection{Literature Review}

No one denies the enormous effect for social media in the lives of people from different age groups. It is estimated that more than $90 \%$ of youth are now using various social media tools, which mirrors the importance of studying its tools in the lives of these age group. The effect of social media was examined from different angles, in sociology, psychology, education, and the majority of previous literature has focused on one or two social media tools, especially Facebook and Twitter, which requires more examination of new social media tools, particularly WhatsApp, one of the most growing social media tools in the last few years as the number of WhatsApp users is growing rapidly, especially after the acquisition of Facebook on WhatsApp two years ago; paying more than 3 Billion US dollars.

This study is based on the Social Exchange Theory (SET), which is one of the most influential theories used for understanding the attitudes and perceptions of people while being engaged in any form of social exchange. As this study is mainly concerned with social media interactions, specifically, understanding the hidden messages of adopting status in the social media medium, and as WhatsApp is one of the most common social media platforms in the last few years, SET assumes that interactions between two individuals serves social purposes, one of the most important is to share information to others. SET assumes that reciprocal exchange relationships begin when one party takes action, and if the other follows suit, subsequent rounds of exchange may begin. Once in motion, the reciprocity cycle is not only a continuous, self-reinforcing one (Clark, 2016).

In the same line of research, Al Ashmawy (2011) postulates that now a days humans are witnessing an era of information and technological revaluation as computers, internet has become a common scene in peoples' average lives. Additionally, information and communication technology and what they provide of tools has impacts the way of living in modern life. It is, therefore, logic to describe this era as a one dominated by the use of different communication tools to be an integral part of our lives. 
Asserting this, both Garcia and Sikstrom (2013) indicate that the last few years have witnessed a revolution in how people are communicating with each other. The emergence of internet and the appearance of social media networks such as Facebook, Twitter and WhatsApp have opened new ventures for the different fields of study. The nature of people ways of connecting with each other, expressing themselves on the social media and status updates are becoming a focal point of view in language fields, especially sociolinguistic, as this has become a new form of language communication containing human activity.

Furthermore, social networking is a growing form of mediated communication tool that provides a new venue for people to document their life experiences and how life is going with them. Thus, seeing other people social networking profiles may be an invaluable source of information about people and their preferences and perceptions. For that reason, a new research interest was the focus on social media status as one way of communicating with other people and a means to understand their personalities (Page, 2010).

With the invention of smartphones, the use of social media networking has prevailed the lives of people in the various age groups. It is now easier to review one's account on the social media anywhere and anytime one wishes to do so, so the chance of communicating with others virtually has increased as the tool to so is available in one's pocket. For these reasons, it is now common to see people share photos, pictures, videos instantly to whom one wishes. This is because estimations indicated that over $70 \%$ of people in the developed countries are now having smartphones, and this percentage reaches more than $90 \%$ among youth in the age group 16-24. Which signifies the popularity of these communication media among this age group of people (Raiman, Antbring, \& Mahmood, 2017). In this aspect, Husni (2013) emphases that the invention of smartphones has marked an information revolution is social media used as individual are no more forced to have a PC or a laptop to access the internet and be connected to the social media. As the new generation has grown up with the emergence of such technology, it has penetrated every human activity and this made it a key pillar in how people act in their daily lives.

Elaborating on this, Al Zamel (2014) argues that the invention of smartphones has provided new applications, and WhatsApp is one of them which has significantly impacted peoples' lives, especially in the Arab World. WhatsApp has revolutionized how people communicate and this started a war against traditional communication tools. As this application is mainly used on the different platforms provided at iPhone, Android or Windows Phone or even on some Nokia cell phones operating with Symbian, WhatsApp can send instant free massages, images and videos using various platforms, this advantage is one of the most important features in it leading to the enormous growing use of WhatsApp as one of the fastest developing social media platform in the last few years. Realizing that WhatsApp is a great threat to the pioneering social media websites and platforms (e.g. Facebook, Twitter, MySpace, Instagram) Facebook maid a hostile takeover on WhatsApp to make it one of its applications as this information and communication giant knows the future forecast both WhatsApp has being the most growing social media website in the last few years despite the fact it was only presented to the world a few years ago (Raiman, Antbring, \& Mahmood, 2017). 


\subsection{Related Studies}

Few studies have examined the status used on WhatsApp as one of the social media tools, and this has made it difficult for the researchers to start from scratch. Anyhow, this section is an attempt to review some related studies that are presented in a chronological order.

Jarvis (2010) investigated status update among Facebook users and its relationship with personality traits. The sample of the study consisted of (126) Facebook users. For data collection, Big-Five Inventory and the Back Depression Inventory were used. The result of the study indicated that Facebook users employ their status to convey their personality traits. It was found in the study that extroversion and openness to experience were significantly and positively related to convoying accurate Facebook status. Depression was a significant predictor of high level of Facebook status update.

Hampton, Goulet, Marlow and Rainie (2012) examined the use level of Facebook among American adults. The sample of the study included (269) adults selected randomly agreeing to participate in the study. For data collection, an online survey was sent to respondents Facebook accounts. The result of the study indicated that the use level of Facebook among the respondents was very high. The study found that the most common reasons for Facebook accounts were getting friends, communicating with family members and communicating personal status.

Deters and Mehl (2013) examined the effect of the Facebook status on individuals" sense of loneliness. The sample of the study included 86 individuals from different age groups and backgrounds. For data collection, the content of their Facebook status was quantitatively analyzed. The results of the study indicated that the Facebook status mirrors the feelings of the user. There were no statistically significant differences due to age and socioeconomic background in the semantic meanings of the Facebook status.

Garcia and Sikstrom (2013) investigated the semantic representations of status updates and its relationship with personality. The sample of the study included (304) of various social media users selected randomly from different age groups. For data collection, a questionnaire and an interview were developed. The results of the study indicated that the increasing numbers of social media status changes communicate several personality flaws such as low self- esteem and mood swings. Users communicate several messages via the use of social media status content such as happiness and sadness. There was a relationship between the increasing changes of social media tools and personality types.

Anglano (2015) used content analysis study design to identify the main features of WhatsApp status semantic meanings. The sample of the study consisted of 23 WhatsApp status which were qualitatively analyzed. The results of the study indicated that some of WhatsApp status profiles do not have a specific meaning for the reader, but, when combined, they may be considered a useful communication tool for those interested in knowing the hidden messages communicated by the profile.

Barnes (2015) investigated the use of social media status for academic purposes among university students. The sample of the study consisted of (214) university students selected randomly. For data collection, a questionnaire was developed and administrated to the sample of the study. It was found in the study that students' use of social media accounts for 
academic purposes is low. The result of the study found that students use social media to keep in touch with their family, friends, past students and peers. The most common reasons for using social media were getting feedback, advice and moral support.

Sanchez-Moya and Cruz-Moya (2015) studied the use of Whatsapp status among university students. The sample of the study consisted of (420) WhatsApp status selected randomly. For data collection, content analysis was used. The result of the study indicated that students from different age group use WhatsApp. It was found that the nature of WhatsApp status included automatically-generated status and self-generated status. The study indicated that the most common uses for WhatsApp status included reinforcing verbal message, adding semantic value and story-telling.

While Aljaad (2017) studied at Saudi Arabia aimed to identify the use of WhatsApp application for academic purposes among female college students. The sample of the study totaled (122) female college students selected randomly. For data collection, a survey questionnaire was used. The result of the study indicated that the use of WhatsApp application was very important for female students as a tool for sharing and accessing academic and educational information.

Aljasir et al. (2017) investigated the main themes mirrored on Facebook status and their semantic meanings among a sample of Saudi university students. The sample of the study totaled 50 male university students. For data collection, thematic analysis was used. The results of the study showed that the main themes found in students' Facebook status were communication with family and close friends, sending messages to specific people, opening a discussion about a certain topic and showing the inner state of the user.

Dar et al. (2017) investigated the use of WhatsApp for medical purposes among medical education students. The sample of the study consisted of (234) medical education students. A questionnaire survey was developed and administrated to the sample students. The result of the study indicated that $88.77 \%$ were using social media for instructional medical purposes. It was found that $25 \%$ of students use social media once or twice a day. There were statistically differences due to gender, in favor of females in the use level of social media.

In another study, Dhar, Chamoli and Kumar (2017) analyzed the content of WhatsApp status as a predictor of personality traits. The sample of the study included (50) university students selected randomly. For data collection, content analysis was used. The result of the study indicated that WhatsApp users update their status from time to time. Reasons for updating WhatsApp status included changes in the personal life and physical well-being. It was found that there is a statistically significant and positive correlation between neuroticism and extraversion personality traits from one hand and the tendency to update Whatsapp status.

Fuentes, Garia and Lopez (2017) analyzed the content of academic group WhatsApp groups among Spanish university students. The sample of the study consisted of (2160) university students subscribing in WhatsApp academic groups selected randomly. For data collection, a content analysis was used. It was found that WhatsApp academic groups are attractive to university students for the easiness of access and the numbers of students subscribing in this application. It was found that the use of WhatsApp application is not limited to information 
sharing purposes, but it is also used to replace face to face communication among student and to share their interest and personal statues.

In another study in the United States of America, Raiman, Antbring and Mahmood (2017) examined the use of WhatsApp application as a tool for communication in academic settings in medical education. The sample of the study consisted of (19) students and (6) faculty members selected using random sample. To achieve the objectives of the study, a total of (582) WhatsApp messages and images were content analyzed. The result of the study indicated that both students and faculty members use WhatsApp application for academic purposes at high levels. The most prevalent uses for WhatsApp application were organizational, educational and social.

Kootbodien, Prasad and Bin Shahkat (2018) examined trends of using WhatsApp application as one tool of communication among university students at United Arab Emirates. The sample of the study consisted (614) university students selected using random sample. For data collection, a survey questionnaire was used. The result of the study indicated that university students considered using WhatsApp as one important communication tool. It was found in the study that the most common use for WhatsApp as a communication tool was for social purposes followed by academic purposes. Reviewing previous studies, it can be noticed that the majority of these studies concentrated on Facebook statuses (e.g. Aljasir, Bajnaid, Elyas, \& Alnawasrah, 2017). Studies that investigated the sociolinguistic functions of WhatsApp statuses are very scarce (Abu Swailam, 2015).

\section{Methods}

The study employs a quantitative method design. The quantitative data collection includes the use of a questionnaire which has been adapted based on previous related studies. to provide a comprehensive investigation of the research questions. The quantitative data collection includes the use of a questionnaire adapted by the researcher based on previous related studies. The reviewed related studies included Aljasir, Bajnaid, Elyas and Alnawasrah (2017), Garcia and Sikstrom (2013). These two studies constituted the theoretical and practical foundation for developing the questionnaire employed as the main source for data collection in this study.

The population of the study included all students who are enrolled at the English department of Jadara and Irbid national Universities in Irbid, Jordan. The sample of the study included (262) students whose ages are between 18-40 (see Table 1). The respondents were informed about the objectives of the study and were ensured that all data obtained from them will be only used for academic research purposes.

Table 1. Characterisitcs of the participants

\begin{tabular}{llll}
\hline & & Frequency & Percent \\
\hline Gender & Male & 83 & 31.7 \\
& Female & 179 & 68.3 \\
& $18-21$ & 168 & 64.1 \\
\hline
\end{tabular}




\begin{tabular}{llll}
\hline Age & $22-26$ & 60 & 22.9 \\
& more than 26 & 34 & 13.0 \\
Marital status & single & 185 & 70.6 \\
& married & 77 & 29.4 \\
Socioeconomic level & less than 300 & 42 & 16.0 \\
& $301-500$ & 138 & 52.7 \\
& more than 500 & 82 & 31.3 \\
& Total & 262 & 100.0 \\
\hline
\end{tabular}

As seen in Table 1, (83) of respondents were male, representing (31.7\%) of the total sample, while (179) were females, and represented (68.3) of the total study sample. Due to age, there was (168) between (18-21) years, with a percent of (64.1\%), (60) students were in the age group from (22-26) with a percent of (22.9\%) and (34) more than 26 years with a percent of (13\%). According to marital status there was (185) single, representing (70.6) of the total sample, while (77) were married, and represented (29.4\%). And according to Socioeconomic level, there was (42) less than 300, representing (16\%) of the total sample, (138) from $301-500$ representing $(52.7 \%)$ of the total sample, and (82) more than 500 representing $(31.3 \%)$ of the total sample

For data collection, a questionnaire consisting of (23) items was developed based on a review of previous related studies to identify WhatsApp use level. The questionnaire was scored using a 5 point Likert scale as follows: $5=$ strongly agree, $4=$ agree, $3=$ neutral, $2=$ disagree, $1=$ slightly disagree. The content and face validity of the questionnaire was achieved by asking a panel of judges, four university professors, to review the content of the questionnaire as their remarks and comments were taken into consideration.

To establish reliability of the questionnaire, a pilot study (test-retest reliability) was prepared using a sample consisting of (50) students selected from out of the original sample. The pilot study subjects responded to the items in the questionnaire, and then were given the same questionnaire with a time interval of (2) weeks. Cronbach's alpha used to test internal consistency, see Table 2 .

Table 2. Cronbach's alpha

\begin{tabular}{cc}
\hline & Values \\
\hline Total & 0.87 \\
\hline
\end{tabular}

These values of Cronbach's alpha were considered enough for the purpose of this study. Percentages, frequencies, standard deviations and means were used to answer the first question of the study. In order to answer the second question, t-tests analysis and one way ANOVA were employed to identify differences among the participants in term of gender, age, marital status and socioeconomic level. 


\section{Al Macrothink}

\section{Results and Discussion}

The present study aims at identifying the level of WhatsApp uses among Jordanians, and to find out if there are any differences among Jordanians in WhatsApp status uses in light of their gender, age, marital status, and socioeconomic level. The present section presents the findings based on the tools used to answer the following research questions:

1) What is the level of WhatsApp use among Jordanians?

2) Are there any differences in Jordanians WhatsApp status uses in light of their gender, age, marital status, and socioeconomic level?

\subsection{The First Research Question: What Is the Level of WhatsApp Use Among Jordanians?}

To answer the first question, mean and standard deviation of the level of WhatsApp use among Jordanians was calculated as shown in Table 3.

Table 3. Means and Standard deviation of the level of WhatsApp use among Jordanian

\begin{tabular}{lll}
\hline Item & Mean & SD \\
\hline Whatsapp use & 3.63 & .553 \\
\hline
\end{tabular}

Table 3 shows that the mean of WhatsApp use was (3.80) which indicates that the level of using WhatsApp application among university students was high. This result can be explained by the fact that the majority of university students own their smartphones as the latest statistics in Jordan, which is that there is more than 10 million smartphones are available among Jordanian people. While considering a very important statistics indicating that the youth, especially university students are the most age group having smartphones, and that WhatsApp is a free application, and that this application provides many important communication tools for university students, and finally the easy access to the internet by Jordanians as it has become available in almost every home and workplace. As such, it is not surprising to find that the use level of WhatsApp application is high among the sample of the study.

Additionally, as WhatsApp provides in the last year new additions such as audiovisual communication, this means that youth can also use it to communicate with their beloved family members and friends in other countries in the Arab Gulf, Europe and United States of America, the high level of using WhatsApp is logic due to what it provides for university students.

Furthermore, it is a common to assume that the advancements in information and communication technology have a very deep impact on the life of people, especially among youth, who are in essence adopting a rebellious stance against the traditional practices and ways of communication dominating the society they belong to. The results can be explained by a common truth and that is WhatsApp is mainly a new information and communication technology with enormous application easy to use and access; making it a part of peoples life. This result is consistent with the results reported in Hampton, Goulet, Marlow and Rainie (2012) study which indicated that the use level of Facebook among the respondents was very high. 
3.2 The Second Research Question: Are There Any Differences in Jordanians WhatsApp Status Uses in Light of Their Gender, Age, Marital Status, and Socioeconomic Level?

For answering this question, means and standard deviations of Jordanians WhatsApp status uses due to gender, age, marital status, and socioeconomic level were used, t-test was used to find out any significant differences according to gender and Marital status variables, while one way ANOVA was used for age and socioeconomic level as shown in tables below.

\subsection{Gender}

Table 4. Means, standard deviation and t-test results according to gender on WhatsApp uses

\begin{tabular}{|c|c|c|c|c|c|c|c|}
\hline & Gender & $\mathrm{N}$ & Mean & SD & $\mathrm{t}$ & $\mathrm{df}$ & $\begin{array}{l}\text { Sig. } \\
\text { (2-ailed) }\end{array}$ \\
\hline \multirow[t]{2}{*}{ QALL } & Male & 83 & 3.52 & .576 & \multirow{2}{*}{2.313} & \multirow{2}{*}{260} & \multirow{2}{*}{.022} \\
\hline & Female & 179 & 3.69 & .535 & & & \\
\hline
\end{tabular}

Table 4 shows there are statistically significant differences at $(\alpha=0.05)$ due to gender variable in favor of females.

\subsection{Marital Status}

Table 5. Means, standard deviation and t-test results according to marital status on WhatsApp uses

\begin{tabular}{|c|c|c|c|c|c|c|c|}
\hline & Marital status & $\mathrm{N}$ & Mean & $\mathrm{SD}$ & $\mathrm{t}$ & df & Sig. (2-tailed) \\
\hline \multirow[t]{2}{*}{ QALL } & Single & 185 & 3.61 & .566 & \multirow{2}{*}{-1.013} & \multirow{2}{*}{260} & \multirow{2}{*}{.312} \\
\hline & Married & 77 & 3.69 & .519 & & & \\
\hline
\end{tabular}

Table 5 shows there are no statistically significant differences at $(\alpha=0.05)$ due to Marital status variable.

\subsection{Age}

Table 6. Means and standard deviations of Whatsapp uses according to age variable

\begin{tabular}{llll}
\hline Age & $\mathrm{N}$ & Mean & Std. Deviation \\
\hline $18-21$ & 168 & 3.68 & .556 \\
$22-26$ & 60 & 3.66 & .533 \\
More than 26 & 34 & 3.37 & .509 \\
Total & 262 & 3.63 & .553 \\
\hline
\end{tabular}

Table 6 shows a slight variance in students' means of Whatsapp uses due to age variable, to find out whether there are statistical significant differences in these means, One way ANOVA was conducted and the results are shown in Tables 6 . 
Table 7. One way ANOVA results of WhatsApp uses according to age

\begin{tabular}{llllll}
\hline Group & Sum of Squares & df & Mean Square & F & Sig. \\
\hline Between Groups & 2.684 & 2 & 1.342 & 4.514 & .012 \\
Within Groups & 76.992 & 259 & .297 & & \\
Total & 79.675 & 261 & & & \\
\hline
\end{tabular}

Table 7 shows there are statistically significant differences at $(\alpha=0.05)$ due to age variable. Pairwise Multiple Comparisons Post Hoc Test using Scheffe method was conducted as in table:

Table 8. Pairwise Multiple Comparisons Post Hoc Tests using Scheffe for age effect

\begin{tabular}{lllll}
\hline (I) Age & $(\mathrm{J})$ Age & Mean Difference (I-J) & Std. Error & Sig. \\
\hline $18-21$ & $22-26$ & .02 & .082 & .979 \\
& more than 26 & $.30(*)$ & .103 & .013 \\
$22-26$ & $18-21$ & -.02 & .082 & .979 \\
& more than 26 & .29 & .117 & .050 \\
more than 26 & $18-21$ & $-.30(*)$ & .103 & .013 \\
& $22-26$ & -.29 & .117 & .050 \\
\hline
\end{tabular}

* The mean difference is signification at the 0.05 levels.

Table 8 shows there are statistically significant difference at $(a=0.05)$ between the age group 18-21 and more than 26 in favor of the age group 18-21.

\subsection{Socioeconomic Level}

Table 9. Means and standard deviations of WhatsApp uses according to socioeconomic level variable

\begin{tabular}{llll}
\hline Level & $\mathrm{N}$ & Mean & Std. Deviation \\
\hline less than 300 & 42 & 3.47 & .606 \\
$301-500$ & 138 & 3.61 & .550 \\
more than 500 & 82 & 3.75 & .509 \\
Total & 262 & 3.63 & .553 \\
\hline
\end{tabular}

Table 9 shows a slight variance in students' means of WhatsApp uses due to socioeconomic level variable, to find out whether there are statistical significant differences in these means, one way ANOVA was conducted and the results are shown in Tables 9. 
Table 10. One way ANOVA results of WhatsApp uses according to socioeconomic level

\begin{tabular}{llllll}
\hline Group & Sum of Squares & df & Mean Square & F & Sig. \\
\hline Between & 2.209 & 2 & 1.105 & 3.693 & .026 \\
Groups & & 259 & .299 & & \\
Within Groups & 77.466 & 261 & & & \\
Total & 79.675 & & & \\
\hline
\end{tabular}

Table 10 shows There are statistically significant differences at $(\alpha=0.05)$ due to socioeconomic level variable. Pairwise Multiple Comparisons Post Hoc Test using Scheffe method was conducted as in Table 10.

Table 11. Pairwise Multiple Comparisons Post Hoc Tests using Scheffe for socioeconomic level effect

\begin{tabular}{lllll}
\hline (I) Socioeconomic & $(\mathrm{J})$ Socioeconomic & Mean Difference (I-J) & Std. Error & Sig. \\
\hline less than 300 & $301-500$ & -.14 & .096 & .343 \\
& more than 500 & $-.28\left(^{*}\right)$ & .104 & .031 \\
$301-500$ & less than 300 & .14 & .096 & .343 \\
\multirow{2}{*}{ more than 500 } & more than 500 & -.13 & .076 & .217 \\
& less than 300 & $.28\left(^{*}\right)$ & .104 & .031 \\
& $301-500$ & .13 & .076 & .217 \\
\hline
\end{tabular}

* The mean difference is signification at the 0.05 levels.

The above table shows there are statistically significant difference at $(a=0.05)$ between less than 300 and more than 500 in favor of more than 500 .

\section{Conclusion and Recommendations}

The study examine the use level of the WhatsApp among Jordanians. Furthermore, this qualitative identified the differences among Jordanians in WhatsApp status uses in light of their gender, age, marital status, and socioeconomic level. The sample of the study consisted (262) students selected randomly. To achieve the aims, a questionnaire was developed based on previous literature and used for data collection. By examining the use level and purposes of this use among university students using WhatsApp and by identifying differences in these practices the researchers have come with the following conclusion.

1) It was found in this study that the use level of WhatsApp application is at high level, meaning that it can be used for achieving several important purposes including academic ones, and this needs for more working on motivating students for more use of this important application for academic purposes.

2) As the study was limited to private universities, there is a need to examine WhatsApp status among public university students in the different geographic regions in Jordan. This is 
a call for future researchers to be more attentive to conducting researches using students from public universities.

\subsection{Limitations and Implications}

The study included an introduction that contains a statement of the problem, the objectives, study questions, and the significance of the study. All recent and related studies were presented in the literature review. The methodology section includes the research design, population and sample of the study, data collection and date analysis procedures. The results of this study carry various theoretical and practical implications for those interested. As for the theoretical implications, the most important is that the results of this study open a new venture for future researchers interested in examining the variables examined in this study in other contexts.

Also, as the sample of the study was limited to private university students, future research may use other students' populations in public universities as this may carry other result from the ones obtained in this study. Furthermore, the sample size used in this study was fairly small and this requires further examination of WhatsApp status using larger student population selected from different universities in Jordan.

\section{References}

Abu Eissa, F., \& Rababah, L. (2020). Exploring Types of Graffiti at Jadara University in Jordan. Journal for the Study of English Linguistics, 8(1), 112-126. https://doi.org/10.5296/ jsel.v8i1.17749

Al_Amri, A., \& Rababah, L. (2020). The Effect of Using YouTube on Developing Elementary Students Vocabulary. Education and Linguistics Research, 6(1), 129-139. https://doi.org/10.5296/elr.v6i1.16796

Abu Swailam, Sarhabeel. (2015). Dependence of Jordanian Universities students on social networking sites to get news and information: Analytical survey. Research Paper, Middle East University, Amman- Jordan.

Alshboul, N., \& Rababah, L. (2021). The emoji linguistic functions on Facebook interactions among undergraduate students at Jadara University in Jordan. Journal for the Study of English Linguistics, 9(1), 43-54. https://doi.org/10.5296/jsel.v9i1.18486

Aljaad, N. (2017). WhatsApp for educational purposes for female students at college of education King Saud University. Education, 137(3), 344-366.

Aljasir, S., Ayman, B., Tariq, E., \& Mustafa, A. (2017). Themes of Facebook Status Updates and Levels of Online Disclosure: The Case of University Students. International Journal of Business Administration, 8(7), 80-97. https://doi.org/10.5430/ijba.v8n7p80

Almwajeh, M., \& Rababah, L. (2019). There is more to it than meets the eye: an intercultural study of religious speech acts between Jordanian and American students. International Journal of Linguistics, 11(1), 34-45. https://doi.org/10.5296/ijl.v11i1.14261

Almwajeh, M., \& Rababah, L. (2018). Literature is the best tool of awaking moral understanding and evaluation: Wendell Berry's The Long-Legged House. AWEJ for Translation \& Literary Studies, 2(2), 69-80. https://doi.org/10.2139/ssrn.3186984

Anglano, C. (2015). Forensic analysis of WhatsApp messenger on android smartphones. 
Psychotherapy Research, 2(5), 214-231.

Banikalef, A., \& Rababah, L. (2018). Gender differences and emotional expressiveness on Facebook: An analysis of prosodic features among Jordanian Facebookers. Studies in Linguistics and Literature, 2(3), 180-184. https://doi.org/10.22158/sll.v2n3p180

Barnes, Naomi. (2015). Facebook status updates about the first year at university: How student experience informs a learner centered transition curriculum. Unpublished $\mathrm{PhD}$ Thesis, Griffith University, Australia.

Dar, Qudsia Anwar, F., A., Muhammad, R., Sadaf, H. K., Khadija, R., Waqar, A., \& Zahid, K. (2017). Use of social media tool "WhatsApp" in medical education. ANNALS, 23(1), 39-42. https://doi.org/10.21649/akemu.v23i1.1497

Deters, F. G., \& Matthias, M. (2013). Does posting Facebook status updates increase or decrease loneliness? An online social networking experiment. Social Psychological and Personality Science, 4(5), 579-586. https://doi.org/10.1177/1948550612469233

Dhar, R., Chamoli, D., \& Kumar, R. (2017). WhatsApp status content and frequency as a predictor of personality trait. The International Journal of Indian Psychology, 4(3), 30-37.

Fuentes, G., Virginia, M. G. D., \& Maria, A. L. (2017). Groups of glass; groups of WhatsApp. Analysis of communicative dynamics among university students. Revista Prisma Social, 18, 144-171.

Garcia, D., \& Sverker, S. (2013). The dark side of Facebook: Semantic representations of status updates predict the Dark Triad of personality. Personality and Individual Differences, 3 , 1-5.

Hamouda, S. B., \& Jalel, A. (2013). Social Networks' text mining for sentiment classification: The case of Facebook' status updates in the "Arabic Spring" era. International Journal of Application or Innovation in Engineering and Management, 2(5), 470-478.

Hampton, K. N., Lauren, S. G., Cameron, M., \& Lee, R. (2012). Why most Facebook users get more than they give: The effect of Facebook 'power users' on everybody else. Pew Research Centers' Internet \& American Life Project, 1-40.

Ilyas, S., \& Qamar, K. (2012). Facebook status updates: A speech act analysis. Academic Research International, 3(2), 500-508.

Jarvis, M. M. (2010). Facebook and personality: What do status updates really communicate?. Unpublished Bachelors Thesis, University of Arizona, USA.

Jdaitawi, M., Ishak. N., Taamneh, M., Gharaibeh, M., \& Rababah, L. (2011). The Effectiveness of Emotional Intelligence Training Program on Social and Academic Adjustment among First Year University Students. International Journal of Business and Social Science, 2(24). 251-258. https://doi.org/10.5539/ijps.v3n2p135

Kootbodien, A., Nunna, V. P., \& Muhamad, S. B. S. A. (2018). Trends and impact of WhatsApp as a mode of communication among Abu Dhabi students. Media Watch, 9(2), 257-266.

Kramer, A. D., \& Cindy, K. Ch. (2011). Dimensions of self-expression in Facebook status updates. Proceedings of the Fifth International AAAI Conference on Weblogs and Social Media. 


\section{Macrothink

Kramer, A. (2010). An unobtrusive model of gross national happiness. Procedia, 2, 287-290. https://doi.org/10.1145/1753326.1753369

Page, R. (2010). Re-examining narrativity: Small stories in status updates. Text \& Talk-An Interdisciplinary Journal of Language, Discourse \& Communication Studies, 30(4), 423-444. https://doi.org/10.1515/text.2010.021

Rababah, L. (2020). Speech act analysis of WhatsApp statuses used By Jordanians. Review of European Studies, 12(2), 28-32. https://doi.org/10.5539/res.v12n2p28

Rababah, L. (2018). An adapted version of Torrance Test of Creative Thinking (TTCT) In EFL/ESL writing: A rubric scoring and a review of studies. International Journal of English and Education (IJEE), 7(2), 128-136.

Rababah, L. (2019). Using Collaborative Learning Strategies to Improve Creativity in EFL Writing: Attitudes and Actual Use. Journal of Education in Black Sea Region, 5(1), 36-52. https://doi.org/10.31578/jebs.v5i1.190

Raiman, L., Richard, A., \& Asad, M. (2017). WhatsApp messenger as a tool to supplement medical education for medical students on clinical attachment. BMC Medical Education, 17(7), 1-9. https://doi.org/10.1186/s12909-017-0855-x

Sanchez, M., \& Cruz, M. (2015). Hey there! I'm using WhatsApp: A preliminary study of recurrent discursive realizations in a corpus of WhatsApp status. Procedia Social and Behavioral Science, 212, 52-60. https://doi.org/10.1016/j.sbspro.2015.11.298

Wani, S. A., Sari, M. R., Sara, A., Nancy, D., \& Yahya, N. (2013). Efficacy of communication amongst staff members at plastic and reconstructive surgery section using smartphone and mobile WhatsApp. Indian Journal of Plastic Surgery, 46, 502-505. https://doi.org/10.4103/ 0970-0358.121990

\section{Copyright Disclaimer}

Copyright reserved by the author(s).

This article is an open-access article distributed under the terms and conditions of the Creative Commons Attribution license (http://creativecommons.org/licenses/by/4.0/). 